\title{
Role Of Transvaginal Sonography, Power Doppler And Hysteroscopy In Women With Abnormal Uterine Bleeding: A Comparative Study
}

\author{
${ }^{1}$ Meena Mayuri, ${ }^{2}$ Singh Abha, ${ }^{3}$ Narula M.K. \\ ${ }^{1}$ MS, Senior Resident, Department of Obstetrics \& Gynecology; SMS Medical College \& Attached Hospitals, \\ Jaipur, Rajasthan, India \\ ${ }^{2} M S$, Director Professor \& Head,Department of Obstetrics \& Gynecolog; Lady Hardinge Medical College, \\ University of Delhi, New Delhi, India \\ ${ }^{3}$ MD, Director Professor \& Head, Department of Radiodiagnosis;Lady Hardinge Medical College, University \\ of Delhi, New Delhi, India.
}

\section{Introduction}

Abnormal uterine bleeding (AUB) generally describes all abnormal patterns of bleeding that may result from a variety of causes, including anovulation, pregnancy, uterine pathology and coagulopathies (1). The prevalence of AUB is estimated to be $11-13 \%$ in the general population and increases with age (2), significantly impacting quality of life and imposing financial burden. Moreover, postmenopausal bleeding is usually the first symptom of endometrial cancer (3) and active intervention can lead to its early detection. So, there is need of a diagnostic tool with high accuracy for detection of endometrial pathology in most efficient and least invasive method possible.

Although several invasive and non-invasive methods like dilatation and curettage, hysteroscopy, transvaginal sonography (TVS) and power Doppler have been proved to be clinically useful for early detection of endometrial abnormality in women with $\operatorname{AUB}(4,5)$, still there is insufficient data comparing the diagnostic accuracies of all three modalities.

The purpose of this study was to evaluate the endometrium in women with AUB using TVS, power Doppler and hysteroscopy and to compare their diagnostic accuracies.

\section{Material and Method}

This observational and cross-sectional study was carried out betweenNovember 1, 2010 and March 31, 2012.The study population was comprised of 69 consecutive women ( $\geq 40$ years) with abnormal uterine bleeding recruited from outpatient clinics of the department of gynecology at a tertiary care center, after taking a written informed consent.

Inclusion criteria: (a) women $\geq 40$ years of age with AUB; (b) women in whom natural menopause was established and who presented with postmenopausal bleeding.

Exclusion criteria: women with cervical cancer, carcinoma breast; history of drug intake like tamoxifen or those on hormone replacement therapy; endocrine disorders like thyroid dysfunction; coagulation disorders; pregnancy and uterine vascular malformations.

Perimenopause is the period associated with mild ovarian hormone deficiency leading to anovulation and menstrual disorders. It usually involves women $>40$ years of age. Any abnormal bleeding during this period is called perimenopausal bleeding. Natural menopause, on the other hand, is the cessation of ovarian function resulting in absence of menses $\geq 1$ year (6).

After a detailed history and thorough examination, each woman underwent Paps smear and lab investigations (blood group, Rh typing, complete blood count, liver and renal function test, coagulation profile, blood sugar and thyroid function test). [Fig 1]

Transvaginal ultrasonography was performed by a qualified radiologist using HDI ATL-5000 model machine with a C 9-5 endovaginal probe and equipped with colour and power Doppler capabilities. First, conventional grayscale sonography was done where the uterus and adnexa were scanned in the longitudinal and transverse planes making note of any abnormality. Double layer endometrial thickness was measured on the midline sagittal scan.Endometrial thickness of $<8 \mathrm{~mm}$ perimenopausal and $<5 \mathrm{~mm}$ in postmenopausal women was considered as normal and a thicker endometrium was classified as abnormal.The power Doppler gate was then activated for blood flow mapping of the endometrium. The power Doppler settings were set to achieve maximum sensitivity for detecting low velocity flow (7). Number, size, regularity of vessel branching and presence of areas of densely packed vessels were then analyzed on power Doppler. 


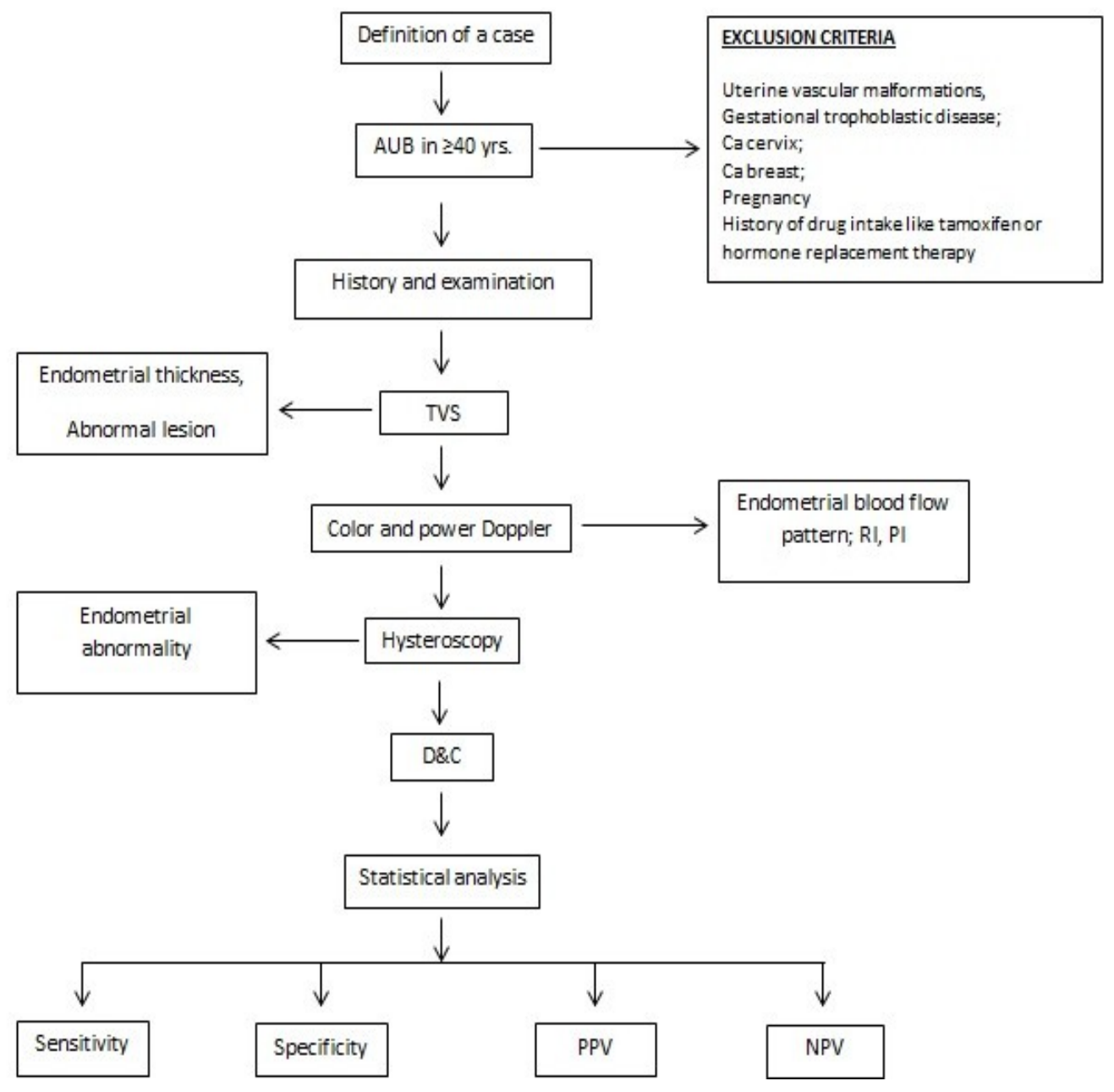

Fig 1: Flow chart depicting the methodology

Three different vascular patterns were defined according to the power Doppler flow mapping (3):

1. Scattered vessel pattern: Here, some scanty vessels were identified within the endometrium and were considered to be characteristic of endometrial hyperplasia. Fig. 2 (a); (b)

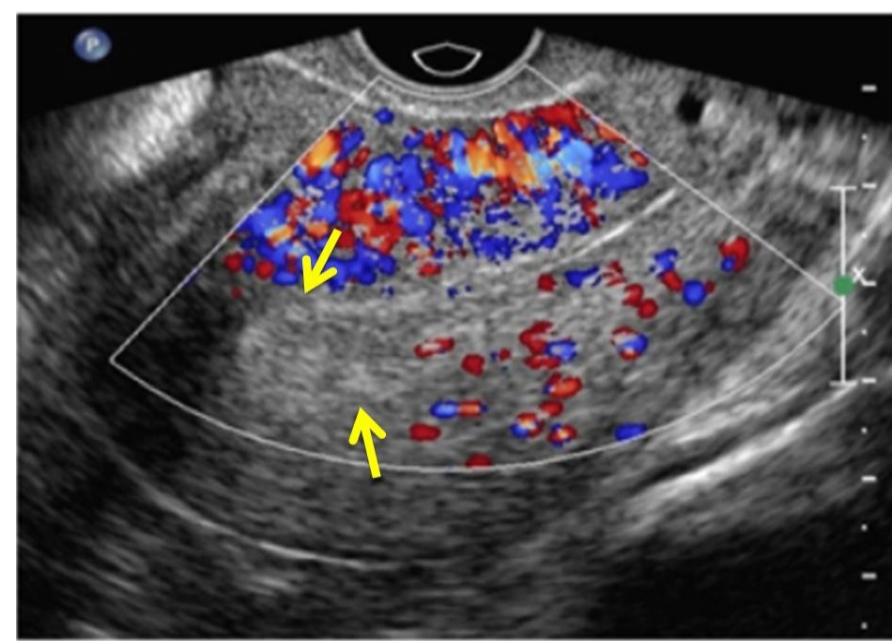

Fig 2 (a): Scattered vessel pattern on color Doppler (arrows marking the endometrium). 


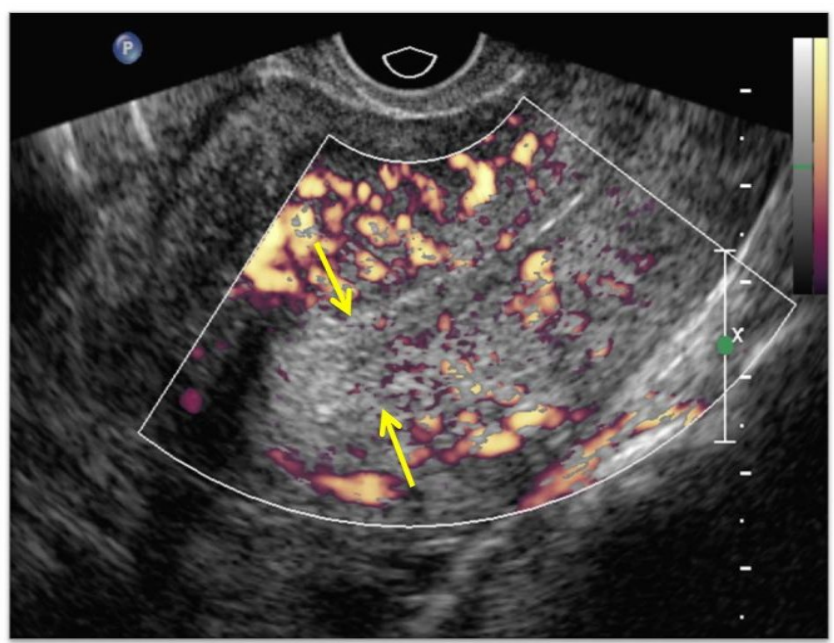

Fig 2(b): Scattered vessel pattern on power Doppler.

2. Single vessel pattern: A single dominant vessel penetrating the endometrium from the myometrium was identified and was considered as characteristic of endometrial polyp.Fig. 3

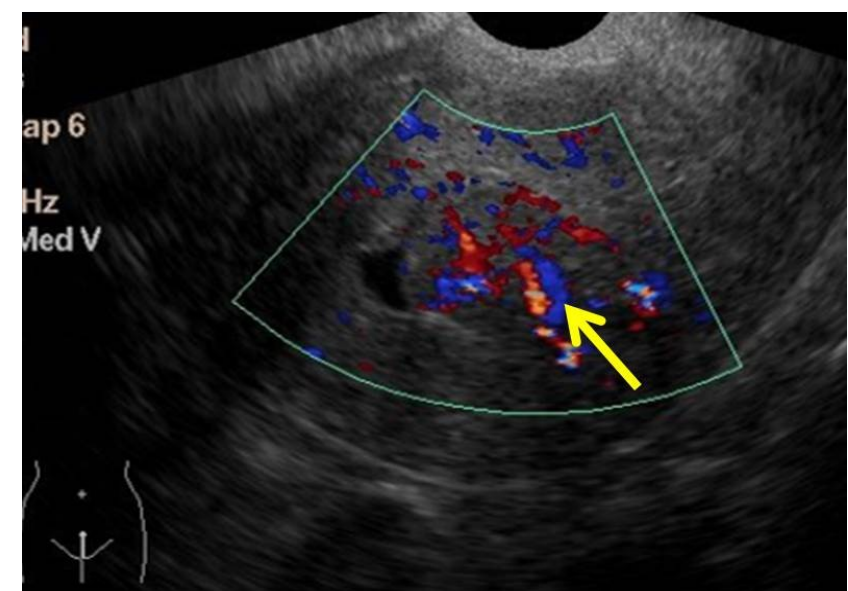

Fig 3: The single vessel pattern typical of endometrial polyp (arrow marking the pedical artery).

3. Multiple-vessel pattern: In this pattern, multiple vessels were found within the endometrium and in the myometrial-endometrial interface. This was considered as characteristic of endometrial cancer. Fig. 4 (a); (b)

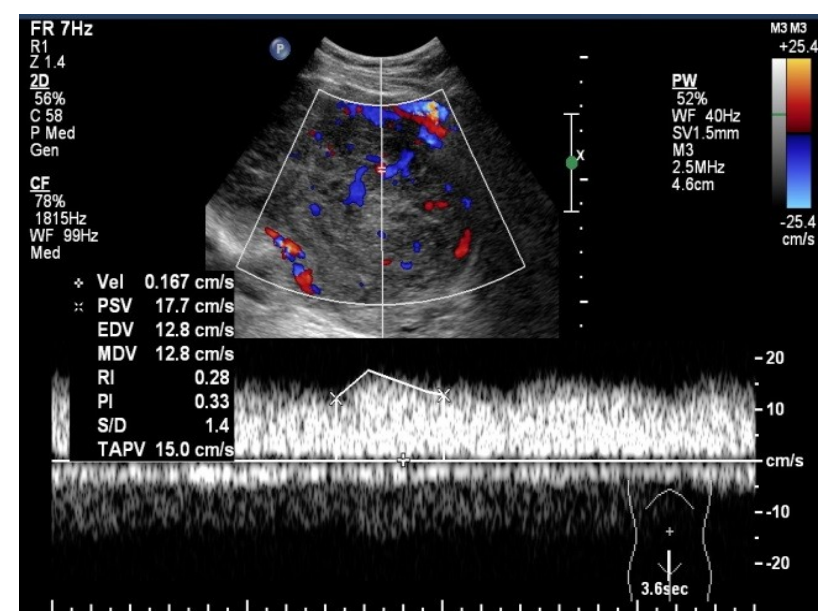

Fig 4(a): Multiple vessel pattern with low resistance flow typical of endometrial carcinoma. 


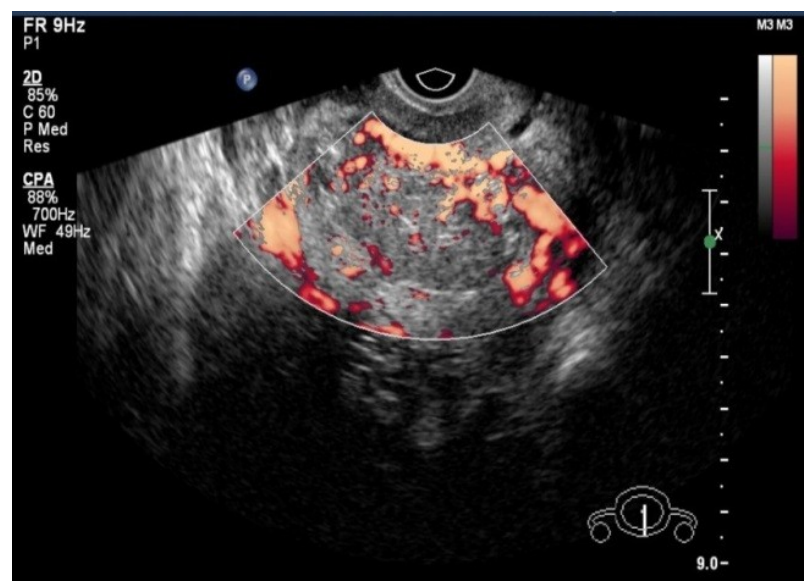

Fig 4(b): Appearance of endometrial carcinoma on power Doppler.

The pulse Doppler was then activated to obtain a flow velocity waveform and the resistance index (RI) and pulsatility index (PI) were obtained.

Hysteroscopy was then performed by a senior gynecologist using rigid hysteroscope-Karl Storz, with 30 degree tilt and $5 \mathrm{~mm}$ diagnostic sheath and normal saline as the distension media. The hysteroscope was guided through the endocervical canal into the uterine cavity under visual control. Systematic inspection of the cervical canal, tubal ostia and the endometrial surfaces was done. Endometrial hysteroscopic features such as normal functional endometrium, atrophic endometrium, mucosal adhesions, polyps, vascular congestion, focal or diffuse increase of the endometrial thickness were recorded. When the inspection of the cavity was complete, the hysteroscope was removed from the uterus. Dilatation \& curettage was then done and tissue obtained was subjected to histological diagnosis, which was considered as 'gold standard' for calculating the diagnostic accuracies of all three modalities.

\section{Statistical analysis:}

All analysis was performed using SPSS 16 software. Data was presented as Mean \pm SD. Categorical data were compared using the chi-square test and student $t$ - test. Sensitivity, specificity, positive predictive value (PPV) and negative predictive value (NPV) were calculated for TVS, each vascular pattern on power Doppler and hysteroscopy. Statistical significance was considered to be achieved at $\mathrm{p}$ values $<0.05$.

\section{Results}

This observational and cross-sectional study was carried out betweenNovember 1, 2010 and March 31, 2012. The study population consisted of 62 perimenopausal $(89.9 \%)$ and seven postmenopausal women $(10.1 \%)$. The mean age of the perimenopausal women was $44.77 \pm 4.47$ years (range $40-55$ years) and that of the postmenopausal women was $53.24 \pm 8.21$ years (range $40-65$ years). The mean age and duration of menopause was $46 \pm 3.7$ years and $7.14 \pm 6$ years respectively. The median age for women with benign and malignant changes of the endometrium was 45.5 years and 48 years respectively.

Demographic characteristics of the study population are shown in Table 1. Mean parity of women with benign lesion was $3.6 \pm 1.5$ as compared to $2.6 \pm 0.8$ of malignant.In perimenopausal women, histology showed normal endometrium in $40(64.5 \%)$, disordered proliferative in seven $(11.3 \%)$, polyp in nine $(14.5 \%)$, senile cystic atrophy in four (6.5\%), endometrial carcinoma and simple hyperplasia without atypia in one (1.6\%) each. On the other hand, in postmenopausal women endometrium was normal in one (14.3\%) and disordered proliferative, senile cystic atrophy and endometrial carcinoma were present in two $(28.6 \%)$ each.

Table 1: Demographic characteristics of the study population

\begin{tabular}{|l|l|l|}
\hline & $\begin{array}{l}\text { Perimenopausal } \\
\mathrm{n}=62\end{array}$ & $\begin{array}{l}\text { Postmenopausal } \\
\mathrm{n}=7\end{array}$ \\
\hline Mean Age (years) & $44.77 \pm 4.47$ & $53.24 \pm 8.21$ \\
\hline Range (years) & $40-55$ & $40-65$ \\
\hline Parity & $3.5 \pm 1.5$ & $3.5 \pm 1.5$ \\
\hline Mean BMI $\left(\mathrm{kg} / \mathrm{m}^{2}\right)$ & $22.02 \pm 1.89$ & $21.57 \pm 2.00$ \\
\hline
\end{tabular}

Three women were not subjected to hysteroscopy due to suspicion of endometrial carcinoma on power Doppler (multiple vessel pattern) andto avoid risk of spread of malignancy. Of the 66 patients subjected to hysteroscopy, 
normal endometrium was seen in $33(50 \%)$,hyperplastic in $18(27 \%)$, endometrial polyp in eight (12\%), atrophy in six $(9.1 \%)$ and submucous fibroid in two $(3 \%)$.

In addition, hysteroscopy was able to diagnose endometritis (4.9\%) intrauterine adhesions (4.5\%) and septum $(6.6 \%)$ which were missed on TVS. Taking histopathology as the gold standard, the overall sensitivity and specificity of hysteroscopy for detecting endometrial pathology was $100 \%$ and $78.5 \%$ respectively (p value $<0.001)$. [Table 2]

Table 2: Diagnostic performance of Hysteroscopy

\begin{tabular}{|c|c|c|c|c|c|}
\hline \multirow[b]{2}{*}{ Diagnosis on Histopathology } & \multicolumn{5}{|c|}{ Hysteroscopy } \\
\hline & Sensitivity & Specificity & PPV & NPV & $\mathrm{p}$ value \\
\hline Abnormal endometrium & 100 & 78.5 & 78 & 100 & $<0.001$ \\
\hline Hyperplasia & 100 & 75.3 & 5.6 & 100 & N.S \\
\hline Disordered Proliferative & 100 & 84.2 & 50 & 100 & N.S \\
\hline Endometrial polyp & 88.9 & 100 & 100 & 98.3 & $<0.001$ \\
\hline Submucous fibroid & 100 & 100 & 100 & 100 & $<0.05$ \\
\hline Senile Cystic Atrophy & 100 & 100 & 100 & 100 & $<0.001$ \\
\hline
\end{tabular}

*N.S- not significant

On TVS, normal endometrium was seen in 42 women, hyperplasia in 14, endometrial polyp in nine, submucous fibroid in one and endometrial carcinoma in three.It was observed that as the endometrial thickness increased to $\geq 8 \mathrm{~mm}$ in perimenopausal women, there was an increase in benign and malignant endometrial pathology ( $p$ value $<0.05)$. The mean endometrial thickness of malignant endometrium $(26 \pm 1.24)$ was significantly higher than benign endometrium $(10.5 \pm 4.0)$ ( $p$ value $<0.05)$. [Table 3 ]

Of the 69 women, power Doppler signals were positive in24 (34.8\%) women and no flow was seen in the rest probably due to normal endometrium in $14(31.1 \%)$, atrophic endometrium in two $(4.4 \%)$, enlarged uterus due to fibroid in $22(48.8 \%)$ and adenomyosis in five $(11.1 \%)$.

Table 3: Mean endometrial thickness of benign and malignant endometrial pathology

\begin{tabular}{|l|c|c|c|c|c|c|c|}
\hline \multirow{2}{*}{ Histopathology } & \multicolumn{5}{|c|}{ Mean endometrial thickness \pm SD (mm) } \\
\cline { 2 - 8 } & EndometrialPolyp & $\begin{array}{c}\text { Submucous } \\
\text { Fibroid }\end{array}$ & Hyperplasia & $\begin{array}{c}\text { Disordered } \\
\text { Proliferative }\end{array}$ & $\begin{array}{c}\text { Cystic } \\
\text { Atrophy }\end{array}$ & \multicolumn{2}{|c|}{$\begin{array}{c}\text { Mean } \\
\text { Carcinoma }\end{array}$} \\
\cline { 2 - 8 } & & $10 \pm 0$ & $8.2 \pm 0$ & $13.6 \pm 4.6$ & $8.75 \pm 1.2$ & $10.8 \pm 3.4$ & $40 \pm 0$ \\
\hline Perimenopausal & $10.6 \pm 2.90$ & $10 \pm 0$ & - & $11.5 \pm 10$ & $7 \pm 4.2$ & $9.25 \pm 7.0$ & $19 \pm 4.2$ \\
\hline Postmenopausal & - & $10 \pm 0$ & $8.2 \pm 0$ & $13.15 \pm 5.5$ & $8.16 \pm 2.3$ & $10.5 \pm 4.0$ & $26 \pm 12.4$ \\
\hline
\end{tabular}

*There were no postmenopausal women with endometrial polyp and submucous fibroid

Taking histopathology as the gold standard, the sensitivity, specificity, PPV and NPV of TVS for diagnosis of endometrial abnormalities were $78.6 \%, 87.8 \%, 81.5 \%$ and $85.7 \%$ respectively ( $p$ value $<0.001$ ). At a cutoff for endometrial thickness of $\geq 8 \mathrm{~mm}$ for perimenopausal women, TVS showed sensitivity, specificity, PPV and NPV of $90.9 \%, 87.5 \%, 80.0 \%$ and $94.5 \%$ respectively. [Table 4 ]

Power Doppler vascular patterns noted were:

- Scattered vessel pattern in $13(18.8 \%)$ women, of which six $(46.5 \%)$ had disordered proliferative endometrium and one (7.6\%) showed hyperplasia on histology.

- $\quad$ Single vessel pattern in eight $(11.5 \%)$ women, of which seven $(87.5 \%)$ had endometrial polyp on histology.

- Multiple vessel pattern in three (4.3\%) women and all of them $(100 \%)$ were found to have endometrial carcinoma on histology.

The diagnostic performance of color Doppler is shown in table 5. The mean resistance index (RI) and pulsatility index $(\mathrm{PI})$ values of benign lesions $(0.66 \pm 0.19$ and $0.92 \pm 0.27$ respectively) were significantly higher than that of carcinoma $(0.33 \pm 0.03$ and $0.45 \pm 0.15$ respectively) (p value $<0.05)$. [Table 6] 
Role Of Transvaginal Sonography, Power Doppler And Hysteroscopy In Women With .....

Table 4: Diagnostic performance of TVS

\begin{tabular}{|c|c|c|c|c|c|}
\hline \multirow[b]{2}{*}{ Diagnosis on Histopathology } & \multicolumn{5}{|c|}{ TVS } \\
\hline & Sensitivity (\%) & Specificity (\%) & $\begin{array}{l}\text { PPV } \\
(\%)\end{array}$ & $\begin{array}{l}\text { NPV } \\
(\%)\end{array}$ & P value \\
\hline Abnormal endometrium & 78.6 & 87.8 & 81.5 & 85.7 & $<0.001$ \\
\hline Hyperplasia without atypia & 100 & 80.0 & 7.1 & 100 & N.S \\
\hline Disorder Proliferative & 66.6 & 86.6 & 42.9 & 94.7 & N.S \\
\hline Endometrial polyp & 77.8 & 93.3 & 63.3 & 96.5 & $<0.001$ \\
\hline Carcinoma & 100 & 100 & 100 & 100 & $<0.001$ \\
\hline Submucous fibroid & 50 & 100 & 100 & 98.5 & N.S \\
\hline
\end{tabular}

*N.S- Not Significant

Table 5: Diagnostic performance of power Doppler

\begin{tabular}{|c|c|c|c|c|c|}
\hline \multirow[b]{2}{*}{ Diagnosis on Histopathology } & \multicolumn{5}{|c|}{ Power Doppler } \\
\hline & Sensitivity (\%) & Specificity (\%) & $\begin{array}{l}\text { PPV } \\
(\%)\end{array}$ & $\begin{array}{l}\text { NPV } \\
(\%)\end{array}$ & p value \\
\hline Simple Hyperplasia & 100 & 100 & 100 & 100 & $<0.001$ \\
\hline Disordered Proliferative & 66.7 & 85 & 40 & 94.4 & N.S \\
\hline Endometrial polyp & 77.8 & 98.3 & 87.5 & 96.7 & $<0.001$ \\
\hline Carcinoma & 100 & 100 & 100 & 100 & $<0.001$ \\
\hline
\end{tabular}

*N.S: Not Significant

Table 6: Velocimetric parameters according to histology

\begin{tabular}{|l|l|l|}
\hline Pathology & \multicolumn{1}{|c|}{ Resistance index (Mean \pm SD) } & \multicolumn{2}{|l}{ Pulsatility index (Mean \pm SD) } \\
\hline Benign & \multicolumn{1}{|l|}{} \\
\hline Endometrial polyp & $0.75 \pm 0.17$ & $1.00 \pm 0.23$ \\
\hline Sub mucosal fibroid & $0.76 \pm 0.05$ & $1.12 \pm 0.25$ \\
\hline Hyperplasia & $0.44 \pm 0$ & $0.6 \pm 0$ \\
\hline Disordered proliferative endometrium & $0.66 \pm 0.15$ & $1.04 \pm 0.23$ \\
\hline Cystic atrophy & $0.75 \pm 0.078$ & $1.00 \pm 0.23$ \\
\hline Carcinoma & $0.33 \pm 0.03$ & $0.45 \pm 0.15$ \\
\hline Overall & $0.66 \pm 0.19$ & $0.92 \pm 0.27$ \\
\hline
\end{tabular}

\section{Discussion}

Abnormal uterine bleeding has a prevalence of about $11-13 \%$ in the general population and has significant impact on the quality of life (2). Several invasive and non-invasive methods like dilatation and curettage, hysteroscopy, TVS and power Doppler have been useful for early detection of endometrial abnormality in women with AUB, but still there is insufficient data comparing the diagnostic accuracies of all three modalities.

In the present study it was seen that benign lesions such as leiomyoma, polyp, adenomyosis were more common in younger women (40-45 years). With the increase in age, more women had hyperplasia, disordered proliferative endometrium, cystic atrophy and carcinoma. Also, endometrial cancer is associated with low parity. Kaur M et al.(8) showed similar results in their study.

Ferrazzi et al. (9)reported that the risk of endometrial cancer increased with increasing body mass index. However, in the present study most of the women belonged to lower socioeconomic status and there were no obese women. So, the traditional prognostic factor of obesity showed no significant association with malignancy, which is consistent with studies by Lieng et al (10) and Savelli et al. (11)

All seven postmenopausal women presented with bleeding per-vaginum and endometrial carcinoma was seen in two of them.Similarly, Rebecca Menzies et al.(12)in their study concluded that malignancy was approximately four times more prevalent in women with bleeding than in asymptomatic women.

Transvaginal sonographic measurement of the endometrial thickness is a non-invasive method which can be used to differentiate benign and malignant lesions of endometrium (13). In the present study endometrial carcinoma was not seen at endometrial thickness of $<5 \mathrm{~mm}$ in postmenopausal and $<8 \mathrm{~mm}$ in perimenopausal women. Goldsteinet al. (14) showed similar results in their study. In perimenopausal women endometrial thickness varies throughout the menstrual cycle. In the preovulatory phase of the cycle endometrial thickness commonly exceeds $8 \mathrm{~mm}$ in a normal uterus. There is a high incidence of abnormalities of the endometrium at a thickness of $\geq 8 \mathrm{~mm}$ in perimenopausal and $\geq 5 \mathrm{~mm}$ in postmenopausal women whereas no pathology is underdiagnosed when a cut off limit of $5 \mathrm{~mm}$ is used (15).

The mean endometrial thickness of malignant lesions, in the present study, was significantly higher than that of benign lesions which was in concordancewith the study done by Karlsson B et al. (16). The present study showed that TVS has a better sensitivity and specificity for diagnosing endometrial abnormality in perimenopausal women at endometrial thickness $\geq 8 \mathrm{~mm}$ as a cut-off limit. These results were in accordance with the study of Conoscenti G et al. (17)where TVS showed sensitivity, specificity, PPV and NPV of $69.3 \%$, 
$82.7 \%, 74.1 \%$ and $72.1 \%$ respectively. Smith $\mathrm{P}$ et al. (18) reported a good agreement between histology and ultrasound at endometrial thickness $\geq 8 \mathrm{~mm}$ where sensitivity, specificity, PPV and NPV were $67 \%, 75 \%, 14 \%$ and $97 \%$ respectively.

Blood flow mapping on power Doppler is a valuable tool in the diagnosis of focal endometrial pathology and is useful in distinguishing submucosal fibroids from endometrial polyps and can also be used to discriminate endometrial carcinoma from other benign pathological processes (19).

The sensitivity, specificity, PPV and NPV of multiple vessel pattern on power Doppler for detecting endometrial carcinoma and scattered vessel pattern for endometrial hyperplasia were $100 \%$ ( $p$ value $<0.001$ ) in the present study. Similarly, Fleischer et al. (19)had also reported that the number of vessels shown on power Doppler correlates with the chances of malignancy. Szpurek D et al. (20) in their study on women with postmenopausal bleeding discovered the presence of 'new, irregular vessels' in $81 \%$ of women with endometrial cancer, in $12 \%$ of women with hyperplasia, but in none with normal endometrium. For detection of endometrial polyps, the pedicle artery sign has sensitivity of $77.8 \%$, specificity of $98.3 \%$, PPV of $87.5 \%$ and NPV of $96.7 \%$ ( $\mathrm{p}$ value $<0.001$ ). This is in accordance with the study by Timmerman $\mathrm{D}$ et al. (21)where the pedicle artery sign had asensitivity of $76.4 \%$, specificity of $95.3 \%$, PPV of $81.3 \%$ and NPV of $93.8 \%$. Alcazar JL et al. (4)have also reported these typical patterns in various endometrial abnormalities.

The RI and PI values were significantly lower in malignant endometrium than in benign diseases of the endometrium in both peri- and postmenopausal women which were comparable with previous studies $(4,22,23,24,25,26)$. Hence, velocimetric parameters on color Doppler have a definitive diagnostic advantage over endometrial thickness for differentiating between benign and malignant endometrium and when combined together can establish a correct diagnosis and aid in proper management which in turn will help to avoid unnecessary invasive procedures in women with abnormal uterine bleeding (27).

Hysteroscopy, showed better sensitivity and specificity over TVS in the detection of endometrial polyp, submucous fibroid and senile atrophy and nearly equal specificity for detecting hyperplasia. Similar results were shown by Tinelli et al. (28) and Yella et al. (29).

TVS had a higher false negative rate for detecting endometrial pathology when compared with hysteroscopy. But since TVS is relatively cheap, easy, needs no anaesthesia and non-invasive, it could be used as a first choice diagnostic test in the investigation of women with abnormal uterine bleeding. In addition, the presence of myometrial invasion in endometrial cancer and other concomitant pelvic pathology can be detected during TVS.

\section{Conclusion}

At a cut-off value for endometrial thickness $\geq 5 \mathrm{~mm}$ in postmenopausal and $\geq 8 \mathrm{~mm}$ in perimenopausal women, ultrasound can be used to rule out endometrial pathology with good certainty. Moreover, power Doppler blood flow mapping in women with abnormal uterine bleeding and thickened endometrium is useful in discriminating benign from malignant pathology. Hysteroscopy, on the other hand, has very high negative predictive value for detection of endometrial abnormality but due to its invasive nature, it should be performed only when endometrial thickness is $\geq 5 \mathrm{~mm}$ in postmenopausal and $\geq 8 \mathrm{~mm}$ in perimenopausal women or abnormal flow is present on power Doppler.

Since the sample size in the present study was small, studies with larger sample size are required to confirm the findings of the present study.

\section{References}

[1.] Fritz M and Speroff L. Clinical Gynaecologic Endocrinology And Infertility 2010. Eighth edition; chapter 15: 592.

[2.] Marret H, Fauconnier A, Chabbert-Buffe. Clinical practice guidelines on menorrhagia: management of abnormal uterine bleeding before menopause. Eur J Obstet Gynecol Reprod Biol. 2010 Oct; 152(2):133-7.

[3.] Alcazar JL, Castillo G, Minguez JA, Galan MJ. Endometrial blood flow mapping using transvaginal power Doppler sonography in women with postmenopausal bleeding and thickened endometrium. Ultrasound Obstet Gynaecol 2003; 21: 583-588.

[4.] Yarandi F, Izadi-Mood N, Eftekhar Z, Shojaei H, Sarmadi S. Diagnostic accuracy of dilatation and curettage for abnormal uterine bleeding. J Obstet Gynaecol Res. 2010 Oct; 36(5):1049-52.

[5.] Ozdemir S, Celik C, Gegine K, Kirese D. Evaluation of endometrial thickness with transvaginal sonography and histopathology in premenopausal women with abnormal vaginal bleeding. Arch Gynecol Obstet. 2010 oct; 282(4): 395-9

[6.] Siobán D, Margery G, Janet E, Roger L. Executive summary of the Stages of Reproductive Aging Workshop + 10: addressing the unfinished agenda of staging reproductive aging. Menopause: The Journal of The North American Menopause Society. Vol. 19, No. 4.

[7.] Bignardi T, Condous G. Is hysteroscopy mandatory in all women with post-menopausal bleeding and thickened endometrium on scan? Australian and New Zealand Journal of Obstetrics and Gynaecology 2009; 49(6): 594-598.

[8.] Kaur M, Singh R, Sharma M. Endovaginal Sonographic Evaluation Of Postmenopausal Uterine Bleeding. Journal of Clinical and Diagnostic Research 2010 April; 4:2175-2182.

[9.] Ferrazzi E, Torri V, Trio D, Zannoni E, Filiberto S, Dordoni D. Sonographic endometrial thickness: a useful test to predict atrophy in patients with postmenopausal bleeding. An Italian multicenter study. Ultrasound Obstet Gynecol 1996; 7: 315-21.

[10.] Lieng M, Qvigstad E, Sandvik L, Jørgensen H, Langebrekke A, Istre O. Hysteroscopic resection of symptomatic and asymptomatic endometrial polyps.J Minim Invasive Gynecol. 2007 Mar-Apr; 14(2):189-94. 
[11.] Savelli L1, De Iaco P, Santini D, Rosati F, Ghi T, Pignotti E, Bovicelli L. Histopathologic features and risk factors for benignity, hyperplasia, and cancer in endometrial polyps.Am J Obstet Gynecol. 2003 Apr; 188(4):927-31.

[12.] Menzies R, Wallace S, Ennis M, Bennett A, Jacobson M. Significance of Abnormal Sonographic Findings in Postmenopausal Women With and Without Bleeding. J Obstet Gynaecol Can 2011; 33(9):944-951.

[13.] Pal L, Lapensee L, Toth TL, Isaacson K. Comparison of office hysteroscopy, transvaginal ultrasonography and endometrial biopsy in evaluation of abnormal uterine bleeding. J Soc Laparoendosc Surg 1997; 1: 125-30.

[14.] Goldstein S. Use of ultrasonohysterography for triage of perimenopausal patients with unexplained uterine bleeding. Am J Obstet Gynecol 1994; 170: 565-70.

[15.] Gupta JK, Chien PF, Voit D, Clark TJ, Khan KS. Ultrasonographic endometrial thickness for diagnosing endometrial pathology in women with postmenopausal bleeding: a meta-analysis. Acta Obstet Gynecol Scand. 2002 Sep; 81(9):799-816.

[16.] Karlsson B, Granberg S, Wikland M, Ylostalo P, Torvid K, Marsal K, et al. Transvaginal ultrasonography of the endometrium in women with postmenopausal bleeding - a Nordic multicenter study. Am J Obstet Gynecol 1995; 172:1488-94.

[17.] Conoscenti G, Meir Y, Fischer-Tamaro L, Maieron A, Natale R. Endometrial assessment by TVS and histological findings after D\&C in women with postmenopausal bleeding. Ultrasound Obstet Gynecol 1995 Aug; 6(2):108-15.

[18.] Smith P, Bakos O, Heimer G, Ulmsten U. Transvaginal ultrasound for identifying endometrial abnormality. Acta Obstet Gynecol Scand. 1991; 70(7-8): 591-4.

[19.] Fleischer AC, Shapell H. Color Doppler sonohysterography of endometrial polyps and submucosal myomas. J Ultrasound Med 2003; 22:601-4.

[20.] Szpurek D, Sajdak S, Moszynski R, Roszak A. Estimation of neovascularization in hyperplasia and carcinoma of endometrium using a 'power' angio-Doppler technique. Eur J Gynaecol Oncol 2000; 21:405.

[21.] Timmerman D, Verguts J, Konstantinovic ML, Moerman P, Schoubroeck D, Deprest J, van Huffel S. The pedicle artery sign based on sonography with color Doppler imaging can replace the second stage tests in women with abnormal vaginal bleeding. Ultrasound Obstet Gynecol 2003 Aug; 22(2):166-7.

[22.] Aleem F, Predanic M, Calame R. Transvaginal color and pulsed Doppler sonography of the endometrium: a possible role in reducing the number of dilatation and curettage procedures. J Ultrasound Med 1995; 14:139-145

[23.] Sheth S, Hamper UM, McCollum ME. Endometrial blood flow analysis in postmenstrual women: can help differentiate benign from malignant causes of endometrial thickening? Radiology 1995; 195:661-665.

[24.] Kurjak A, Kupesic S, Sparac V, Bekavac I. Preoperative evaluation of pelvic tumors by Doppler and three-dimensional sonograghy. J Ultrasound Med 2001; 20: 829-840.

[25.] Kupesic-Urek S, Shalan H, Kurjak A. Early detection of endometrial cancer by transvaginal color Doppler. European Journal of Obstetrics \& Gynecology and Reproductive Biology 1993; 49 (1-2): 46-49.

[26.] Kupesic-Urek S, Shalan H, Kurjak A. Early detection of endometrial cancer by transvaginal color Doppler. European Journal of Obstetrics \& Gynecology and Reproductive Biology 1993; 49: 46-49.

[27.] Aboul-Fotouh ME, Mosbeh MH, El-Gebaly AF. Transvaginal power Doppler sonography can discriminate berween benign and malignant endometrial conditions in women with postmenopausal bleeding. Middle Ease Fertility Society journal 2012;17:22-29

[28.] Tinelli R, Tinelli FG, Cicivelei E, Tinelli A. The role of hysteroscopy with eye directed biopsy in postmenopausal women with uterine bleeding and endometrial atrophy. Menopause 2008;15: 737-742

[29.] Yela DA, Ravacci SH, Monteiro IM, Pereira KC, Gabiatti JR. Comparative study of transvaginal sonography and outpatient hysteroscopy for detection of pathologic endometrial lesions in postmenopausal women. Rev Assoc Med Bras. 2009 Sep-Oct; 55:553-6. 